\title{
Substituent effects on the mechanism changeover in a multi- pathway reaction: a model for the behavior of biological systems?
}

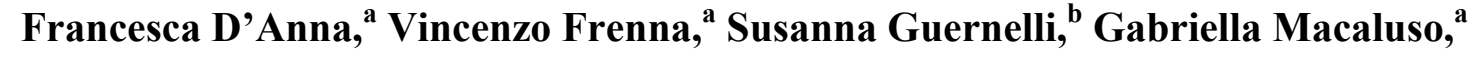 \\ Giovanni Petrillo, ${ }^{c}$ Egon Rizzato, ${ }^{b}$ and Domenico Spinelli ${ }^{\mathrm{b}}$ *
}

${ }^{a}$ Dipartimento di Chimica Organica 'E. Paternò', Università di Palermo, Viale delle Scienze, Parco d'Orleans 2, 90128 Palermo, Italy

${ }^{b}$ Dipartimento di Chimica Organica 'A. Mangini', Università di Bologna, Via San Giacomo 11, 40126 Bologna, Italy

${ }^{c}$ Dipartimento di Chimica e Chimica Industriale, Via Dodecaneso 31, 16146 Genova, Italy

E-mail: domenico.spinelli@unibo.it

\begin{abstract}
Dedicated to Professor H. C. van der Plas on the occasion of his $80^{\text {th }}$ birthday, remembering his fundamental contribution to the development of heterocyclic chemistry
\end{abstract}

\begin{abstract}
By studying the rearrangement in dioxane/water of a series of $(Z)$-arylhydrazones of 5-amino-3benzoyl-1,2,4-oxadiazole (1a-k) into the relevant (2-aryl-5-phenyl-2H-1,2,3-triazol-4-yl)ureas (2a-k) in a wide range of $\mathrm{pS}^{+}$(an operational scale of proton concentration in the mixed solvent used; dioxane/water, 1:1, v:v), the occurrence of three different reaction pathways (specific-acidcatalyzed, uncatalyzed, and general-base-catalyzed) for the relevant $\mathrm{S}_{\mathrm{N}} \mathrm{i}$ process has been recently enlightened. The significantly different substituent effects on the three pathways cause some crossovers in the $\log k_{\mathrm{A}, \mathrm{R}}$ versus $\mathrm{p} S^{+}$plots. Both the $\mathrm{p} S^{+}$value at which the crossover occurs and the width of the uncatalyzed pathway appear in turn substituent-dependent. Thus, thanks to the wide and complete range of substituents examined, the data obtained have been treated by using free-energy relationships. Interestingly enough, these results also furnish valuable information concerning the effects of "small" variations in chemical structures able to produce "large" reactivity variations in some way recalling what can occur in biological systems.
\end{abstract}

Keywords: Monocyclic rearrangements, multi-pathway reactions, base-catalysis, acid-catalysis, changeover of mechanism, model for enzymes 


\section{Introduction}

Five-member nitrogen heterocycles represent powerful means for realizing organic syntheses ${ }^{1-4}$ and are largely used in medicinal ${ }^{5}$ and in veterinary chemistry ${ }^{6}$ as well as in material science. ${ }^{7}$

In the framework of our studies on the synthetic applications ${ }^{4 a, b, 8}$ and on the mechanisms ${ }^{4 a, b, 9}$ of the azole-to-azole rearrangements, we have recently provided evidence of the interesting effect of a 5-amino substituent in the 1,2,4-oxadiazole ring on the rearrangement of some (Z)arylhydrazones of 3-benzoyl-1,2,4-oxadiazole (1a-k) ${ }^{9 \mathrm{e}, \mathrm{h}}$ It is able to open the way to a specificacid-catalyzed pathway in the "monocyclic rearrangement of heterocycles" (MRH, as named by Boulton and Katritzky). ${ }^{4}$ Thus, it was observed that $\mathbf{1 a}-\mathbf{k}$ in dioxane/water (D/W, 1:1, v:v) could rearrange into the relevant (2-aryl-5-phenyl-2H-1,2,3-triazol-4-yl)ureas (2a-k) in a wide range of proton concentration $\left(\mathrm{p} S^{+} 0.1-12.3 ; \mathrm{p} S^{+} \text {is an operational } \mathrm{pH} \text { scale in } \mathrm{D} / \mathrm{W}\right)^{10}$ via three different reaction routes (Scheme): specific-acid-catalyzed, uncatalyzed and general-base-catalyzed.

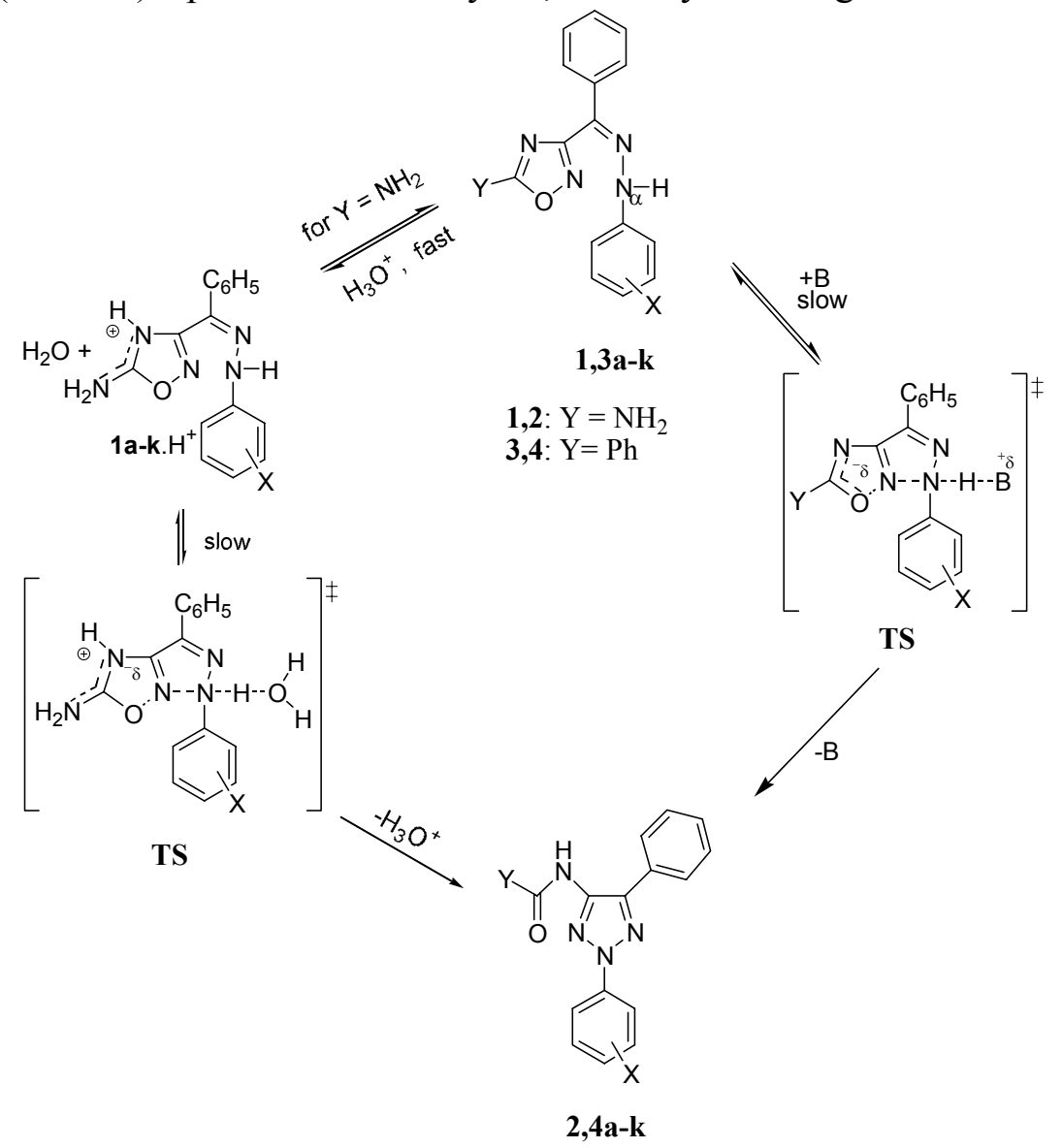

\section{Scheme}

$$
\begin{aligned}
& \text { a: } \mathrm{X}=4-\mathrm{OMe} \quad \text { e: } \mathrm{X}=4-\mathrm{Cl} \quad \text { i: } \mathrm{X}=3-\mathrm{NO}_{2} \\
& \text { b: } X=4-\mathrm{Me} \quad \text { f: } X=4-\mathrm{Br} \quad \text { j: } X=4-\mathrm{CN} \\
& \begin{array}{lll}
\text { c: } X=3-\mathrm{Me} & \text { g: } \mathrm{X}=3-\mathrm{Cl} & \text { k: } \mathrm{X}=4-\mathrm{NO}_{2}
\end{array} \\
& \text { d: } \mathrm{X}=\mathrm{H} \quad \mathbf{h}: \mathrm{X}=3-\mathrm{Br} \\
& \mathrm{B}=\text { water, dioxane, hydroxide or borate ions }
\end{aligned}
$$


On the right side of the scheme the TS for the general-base-catalyzed (B = hydroxide or, e.g., borate ions) and for the uncatalyzed pathways $(\mathrm{B}=$ water or dioxane $)$ is depicted. On the left side protonation equilibrium and TS are depicted for the specific-acid-catalyzed pathway.

In nucleophilic substitutions, the ability of simple systems to show all of the three alternative kinds of reactivity observed for $\mathbf{1 a}-\mathbf{k}$ at different proton concentrations is quite unusual. ${ }^{11}$ As a matter of fact such an occurrence would require the presence of: $(a)$ an acidic center able to react with bases to give the base-catalyzed path; $(b)$ a basic center able to react with acids to give the acid-catalyzed path; (c) an effective nucleophilic center able to give, as such, the uncatalyzed path.

Such a concurrence, which is not frequent in simple molecules, ${ }^{12}$ is on the other hand quite normal for complex molecular systems containing several functional groups such as enzymes; ${ }^{12}$ as a matter of fact, enzymatic processes take definite advantage of the presence (in the surrounding of the active site) of both basic and acidic lateral-chain groups to provide assistance e.g. to the proton transfers which accompany the specific enzyme-catalyzed reaction process. While enzymes can accomplish such polyfunctional catalysis within narrow $\mathrm{pH}$ ranges thanks to the possibility of selecting proper acidic and basic groups, sizeable $\mathrm{p} S^{+}$changes are needed herein in order to bring different catalytic mechanisms to evidence.

Thus, according to the left side of the Scheme, in 1a-k the presence of the strong electronreleasing 5-amino group $\left(\sigma_{p \text {-NH2 }}^{+}-1.30\right),{ }^{12 \mathrm{e}}$ enforces the protonation at $\mathrm{N}(4)$ of the $1,2,4$ oxadiazole ring and opens the way to a specific-acid-catalyzed path $^{9 \mathrm{f}}$ in strongly acidic conditions. Examining the right side of the Scheme, instead, it appears that the nucleophilic character of the $\mathrm{sp}^{3}$-hybridized nitrogen (the $N_{\alpha}$ atom) of the arylhydrazono moiety allows an uncatalyzed path. ${ }^{9 a, b, g}$ Finally, the acidic character of the proton $\left(\mathrm{N}_{\alpha}-H\right)$ of the arylhydrazono moiety makes a general-base-catalyzed pathway ${ }^{9 \mathrm{a}, \mathrm{c}, \mathrm{d}}$ viable too.

The occurrence of the above paths depends on the peculiar nature of the nucleophilic substitution involved: intramolecular $\left(\mathrm{S}_{\mathrm{Ni}}\right)$ and able to give a $2 H-1,2,3$ - triazole, i.e. a 5-member heterocycle (cyclizations to give 5- and 6-member rings are strongly favored) ${ }^{13}$ much more aromatic than the starting 1,2,4-oxadiazole one. ${ }^{14,15}$ Intramolecular processes can show very high effective molarities ${ }^{13 c, 16}$ and can be several orders faster than corresponding non-intramolecular processes. In our case it has been observed that the 1,2,4-oxadiazole ring-opening does not occur by the action of external nucleophiles also if they are much more effective than the arylhydrazono nitrogen. , $^{4, b, 9 e, 13 b}$

We have pointed out that the $\mathrm{S}_{\mathrm{Ni}}$ reaction occurs via a concerted bond-forming $\left[\mathrm{N}_{\alpha}-\mathrm{N}(2)\right]$ and bond-breaking $[\mathrm{N}(2)-\mathrm{O}(1)]$ process and involves ten electrons in a bicyclic (quasi-aromatic) transition state. ${ }^{9 g}$ Its evolution is favored by the fact that the $\mathrm{N}(2)-\mathrm{O}(1)$ bond breakage provides, as leaving group, the highly resonance-stabilized ureido group eventually linked to $\mathrm{C}(4)$ of the final, truly aromatic 1,2,3-triazole.

The kinetic data obtained by studying the rearrangement of $\mathbf{1} \mathbf{a}-\mathbf{k}$ [a reactivity logarithmic plot of $\log k_{\mathrm{A}, \mathrm{R}}$ for some significant (Z)-arylhydrazones versus $\mathrm{p} S^{+}$is reported in Figure 1] have been examined by means of free-energy relationships (Yukawa-Tsuno or Ingold-Yukawa-Tsuno 
equations, see Figures 5-7 in Supplementary Information (S.I.), as well as cross-correlations) ${ }^{9 \mathrm{i}}$ obtaining mechanistic information useful for the understanding of the very nature of the processes occurring. As a matter of fact the substituent on the hydrazono moiety can exert different effects on the three reaction pathways, making each of them effectively contribute to the rearrangement in different $\mathrm{p} S^{+}$ranges. ${ }^{9 i}$ E.g. strong electron-withdrawing groups, such as nitro or cyano groups, favor the base-catalyzed path and in contrast disfavor the uncatalyzed as well as the acid-catalyzed path. Electron-donating substituents, such as methoxy and methyl groups, exert opposite effects.

The substituent-dependence of the reactivity on the proton concentration gives rise to some crossovers in the $\log k_{\mathrm{A}, \mathrm{R}}$ versus $\mathrm{p} S^{+}$plots (Figure 1) and the switch from one mechanism to the other (that we shall indicate as "break-point") occurs at substituent-dependent $\mathrm{p} S^{+}$values. This makes in turn the width of the uncatalyzed pathway substituent-dependent.

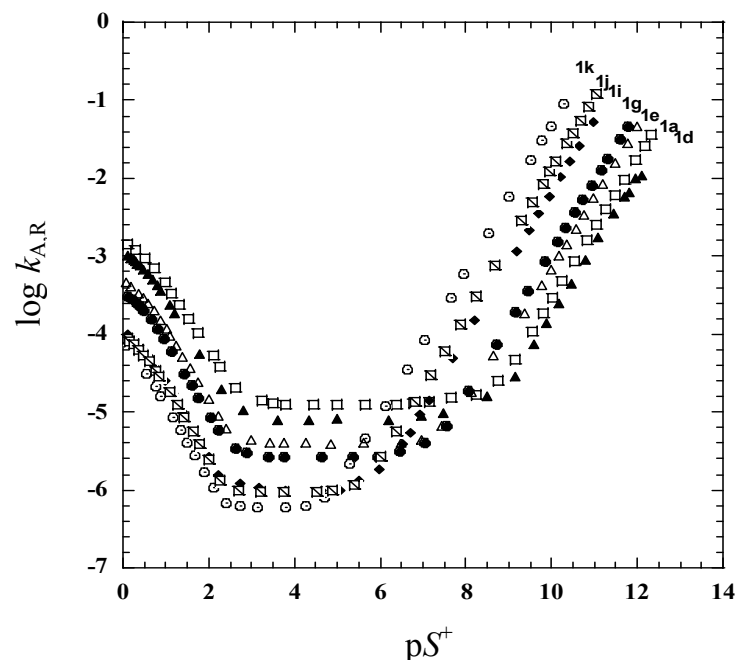

Figure 1. Plot of $\log k_{\mathrm{A}, \mathrm{R}}\left(k_{\mathrm{A}, \mathrm{R}}\right.$ : apparent rate constants for the rearrangement) in $\mathrm{D} / \mathrm{W}$ at $313.1 \mathrm{~K}$ for the rearrangement of $\mathbf{1 a}, \mathbf{1 d}, \mathbf{1 e}, \mathbf{1 g}, \mathbf{1} \mathbf{i}, \mathbf{1} \mathbf{j}$, and $\mathbf{1 k}$ into the relevant triazoles versus $\mathrm{p} S^{+}$.

The wide range of substituents examined in the rearrangement should allow a quantitative examination of the substituent effects both on the reaction pathways changeover and on the width of the uncatalyzed region. These results encompass a double interest: they can contribute to further clarify the mechanism of MRH and at the same time they can behave as "models" and provide information on the behavior of complex biological systems, such as enzymes. 


\section{Results and Discussion}

Examination of the substituent effects on the changeover between reaction pathways. Figure 1 clearly shows that, for the rearrangement in D/W of the $(Z)$-arylhydrazones 1 into the relevant triazoles $\mathbf{2}$, the break-point value, e.g. from the base-catalyzed to the uncatalyzed path, is strongly substituent-dependent. This observation has induced us to investigate this point on more quantitative grounds. Actually, the break-point is the intersection between the straight lines relevant to the base-catalyzed and the uncatalyzed paths and represents the value at which the substrate shows the same reactivity in the two paths [the Table 1 collects such break-point values, indicated as $\left.\left(\mathrm{p} S^{+}\right)_{1}\right]$. One can observe that, depending on the nature of the substituent, these break-points fall in a $S^{+}$range between 4.75 (for $\mathbf{1 k}$ ) and 8.8 (for $\mathbf{1 a}$ ).

For the sake of comparison, also the break-points concerning the rearrangement of the $(Z)$ arylhydrazones of 3-benzoyl-5-phenyl-1,2,4-oxadiazole (3a-k) into the relevant 2-aryl-4benzoylamino-5-phenyl-2H-1,2,3-triazoles $(\mathbf{4 a - k})^{9 \mathrm{~d}}$ are reported in the Table 1.

An analogous situation occurs for the changeover from the uncatalyzed to the acid-catalyzed pathway: the relevant break-points $\left[\left(\mathrm{pS}^{+}\right)_{2}\right]$ are collected in Table, evidencing a similar, but a significantly narrower range (from $\mathrm{p} S^{+} 2.3_{5}$ for $\mathbf{1 k}$ to 2.8 for $\mathbf{1 a}$ ).

In both cases $\left[\left(\mathrm{p} S^{+}\right)_{1}\right.$ and $\left.\left(\mathrm{p} S^{+}\right)_{2}\right]$ strongly electron-releasing groups [for example, 4-MeO $\left(\sigma_{p \text {-OMe }}^{+}-0.78\right),{ }^{12 \mathrm{e}}$ as in 1a] and electron-withdrawing groups [for example, 4- $\mathrm{NO}_{2}\left(\sigma_{p-\mathrm{NO}_{2}}^{-}\right.$ $+1.25),{ }^{12 \mathrm{e}}$ as in $\mathbf{1 k}$ ] shift the break-point towards higher and lower $\mathrm{p} S^{+}$, s, respectively.

The data above indicate that in the case of $(Z)$-arylhydrazones containing a strong electronreleasing group (for example, 1a) the uncatalyzed process is effective in a $\mathrm{p} S^{+}$range (from 2.8 to 8.8) much larger than that observed in the case of a $(Z)$-arylhydrazone containing a strong electron-withdrawing group (for example, 1k), for which the uncatalyzed process is effective only in a restricted $\mathrm{p} S^{+}$range (i.e. from $2.3_{5}$ to $4.7_{5}$ ).

This behavior fits very well with our previous results on the mechanism of the uncatalyzed path in MRH processes: ${ }^{9 \mathrm{~b}, \mathrm{~g}}$ as a matter of fact, an increase of the nucleophilicity of $\mathrm{N}_{\alpha}$ (caused by an electron release from the aryl of the arylhydrazono residue) favors the nucleophilic attack and then widens the $\mathrm{p} S^{+}$range at which the uncatalyzed process can effectively operate. 
Table 1. Slopes of the straight lines for the catalyzed ranges, ${ }^{a}$ break-points $\left[\left(\mathrm{p} S^{\dagger}\right)_{1}\right.$ and $\left.\left(\mathrm{p} S^{+}\right)_{2}\right]$ for the changeover of mechanisms, ${ }^{b}$ and widths $\left(\Delta \mathrm{p} S^{+}\right)$of the uncatalyzed pathway ${ }^{b}$ for the rearrangement of 1a-k into $2 \mathbf{a}-\mathbf{k}$ at various $\mathrm{p} S^{+}$in $\mathrm{D} / \mathrm{W}(1: 1, \mathrm{v}: \mathrm{v})$ and at $313.1 \mathrm{~K}$

\begin{tabular}{|c|c|c|c|c|c|}
\hline & $\begin{array}{c}\text { Slopes } \\
\text { (base catalysis) }^{c}\end{array}$ & $\left(\mathrm{p} S^{+}\right)_{1}{ }^{c}$ & $\begin{array}{c}\text { Slopes } \\
\text { (acid catalysis) }\end{array}$ & $\left(\mathrm{p} S^{\dagger}\right)_{2}$ & $\Delta \mathrm{p} S^{+d}$ \\
\hline $1 a$ & $\begin{array}{c}0.920 \\
(0.928)\end{array}$ & $\begin{array}{c}8.80 \\
(8.04)\end{array}$ & -0.820 & 2.82 & 5.98 \\
\hline $1 b$ & $\begin{array}{c}0.920 \\
(0.925)\end{array}$ & $\begin{array}{c}8.68 \\
(7.98)\end{array}$ & -0.831 & 2.80 & 5.88 \\
\hline $1 \mathrm{c}$ & $\begin{array}{c}0.912 \\
(0.916)\end{array}$ & $\begin{array}{c}8.61 \\
(7.91)\end{array}$ & -0.869 & 2.77 & 5.84 \\
\hline 1d & $\begin{array}{c}0.891 \\
(0.905)\end{array}$ & $\begin{array}{c}8.51 \\
(7.89)\end{array}$ & -0.900 & 2.73 & 5.78 \\
\hline $1 e$ & $\begin{array}{c}0.916 \\
(0.906)\end{array}$ & $\begin{array}{c}7.56 \\
(6.89)\end{array}$ & -0.911 & 2.62 & 4.94 \\
\hline 1f & $\begin{array}{c}0.902 \\
(0.905)\end{array}$ & $\begin{array}{c}7.33 \\
(6.66)\end{array}$ & -0.927 & 2.60 & 4.73 \\
\hline $1 g$ & $\begin{array}{c}0.913 \\
(0.919)\end{array}$ & $\begin{array}{c}7.12 \\
(6.47)\end{array}$ & -0.931 & 2.57 & 4.55 \\
\hline $1 \mathrm{~h}$ & $\begin{array}{c}0.923 \\
(0.924)\end{array}$ & $\begin{array}{c}7.09 \\
(6.37)\end{array}$ & -0.939 & 2.55 & 4.54 \\
\hline $1 \mathrm{i}$ & $\begin{array}{c}0.921 \\
(0.926)\end{array}$ & $\begin{array}{c}5.85 \\
(5.19)\end{array}$ & -0.966 & 2.44 & 3.41 \\
\hline $1 \mathrm{j}$ & $\begin{array}{c}0.930 \\
(0.942)\end{array}$ & $\begin{array}{c}5.56 \\
(4.95)\end{array}$ & -0.968 & 2.41 & 3.15 \\
\hline $1 k$ & $\begin{array}{c}0.932 \\
(0.935)\end{array}$ & $\begin{array}{c}4.75 \\
(4.12)\end{array}$ & -0.970 & 2.35 & 2.40 \\
\hline
\end{tabular}

${ }^{a}$ Data from ref. 9i, uncertainty $\pm 0.5 \% .{ }^{b}$ Uncertainty $\pm 1 \% .{ }^{c}$ In parentheses, the slopes and the break-points for the rearrangements of $3 \mathbf{a}-\mathbf{k}$ into $4 \mathbf{a}-\mathbf{k}$ in comparable experimental conditions are reported. ${ }^{d} \Delta \mathrm{p} S^{+}=\left(\mathrm{p} S^{+}\right)_{1}-\left(\mathrm{p} S^{+}\right)_{2}$.

On more quantitative grounds, as only the specific-acid catalyzed, uncatalyzed and generalbase-catalyzed routes are operative in the rearrangement of $\mathbf{1 a - k}$, the simplified kinetic expression of eq 1 holds ${ }^{12}$

$$
k_{\mathrm{A}, \mathrm{R}}=k_{\mathrm{u}}+K k_{\mathrm{H}}\left[\mathrm{H}_{3} \mathrm{O}^{+}\right] /\left(1+K\left[\mathrm{H}_{3} \mathrm{O}^{+}\right]\right)+k_{\mathrm{OH}}\left[\mathrm{OH}^{-}\right]+\Sigma k_{\mathrm{B}}[\mathrm{B}]
$$

By inserting in eq 1 the experimental values of the relevant kinetic and thermodynamic parameters [e.g., for $1 \mathbf{d}$ at $298.1 \mathrm{~K}^{9 \mathrm{9f,i}} k_{\mathrm{u}} 1.210^{-6} \mathrm{~s}^{-1} ; K(1.23 \pm 0.02) \mathrm{L} \mathrm{mol}^{-1} ; k_{\mathrm{H}}(1.58 \pm 0.01)$ $10^{-4} \mathrm{~L} \mathrm{~mol}^{-1} \mathrm{~s}^{-1} ; k_{\mathrm{OH}}(5.67 \pm 0.07) \mathrm{L} \mathrm{mol}^{-1} \mathrm{~s}^{-1}$ and $\left.k_{\mathrm{B}}(0.021 \pm 0.001) \mathrm{L} \mathrm{mol}^{-1} \mathrm{~s}^{-1}\right]^{9 f, \mathrm{i}}$ one can observe 
that at high proton or base (hydroxide ion plus buffer base) concentrations only the specific-acidcatalyzed or the general-base-catalyzed pathway can be observed, respectively.

In contrast, there is a $\mathrm{pS}^{+}$range, depending on the nature of the substituent, where the concentrations of the catalysts (the proton or the present bases) are so small that only the uncatalyzed pathway is effective $\left[k_{\mathrm{u}}>K k_{\mathrm{H}}\left[\mathrm{H}_{3} \mathrm{O}^{+}\right] /\left(1+K\left[\mathrm{H}_{3} \mathrm{O}^{+}\right]\right)\right.$and $k_{\mathrm{u}}>\left(k_{\mathrm{OH}}\left[\mathrm{OH}^{-}\right]+\Sigma\right.$ $\left.\left.k_{\mathrm{B}}[\mathrm{B}]\right)\right]$ : i.e. $k_{\mathrm{A}, \mathrm{R}}=k_{\mathrm{u}}$.

Within the framework just outlined one can therefore put the following questions:

1) Does a relationship exist between the $\left(\mathrm{p} S^{+}\right)_{1}$ or $\left(\mathrm{p} S^{+}\right)_{2}$ values ${ }^{17}$ and the substituent effects? Because of the extended set of substituents present in the arylhydrazono moiety $\left(n 11\right.$, with $\sigma_{\mathrm{H}}$ values ranging between -0.28 and $+0.78 ;{ }^{12 \mathrm{e}}$ anyway, considering that $\sigma^{+}$and $\sigma^{-}$values would be used in some calculations, the range could become $>2$ ), for the first time proofs on such a correlation could be collected.

2) In the instance of $\left(\mathrm{p} S^{+}\right)_{1}$, is there any significant difference between the behavior of the $(Z)$ hydrazones $\mathbf{1} \mathbf{a}-\mathbf{k}$ and $\mathbf{3 a}-\mathbf{k}$ ?

3) Moreover, is there a relationship between the width of the uncatalyzed region [i.e. $\Delta \mathrm{p} S^{+}=$ $\left.\left(\mathrm{p} S^{+}\right)_{1}-\left(\mathrm{p} S^{+}\right)_{2}\right]$ and the electronic substituent effect?

Hereinafter, answers to the above questions will be suitably provided.

1) As far as the $\left(\mathrm{p} S^{+}\right)_{1}$ values for $\mathbf{1 a}-\mathbf{k}$ are concerned, we have searched for a FER, obtaining an excellent correlation from the Yukawa-Tsuno treatment ${ }^{18}$ by using $\sigma^{\mathrm{n}}$ substituent constants, ${ }^{19}$ finding evidence for a large contribution of through-resonance ${ }^{18}$ by electron-withdrawing substituents (eq 2: $n=11, r=0.998, i=-0.07 \pm 0.04$, C.L. $>99.9 \%$, Figure 2 ; see also Figure 8 in the S.I.).

$$
\delta\left(\mathrm{p} S^{+}\right)_{1}=\left[\left(\mathrm{p} S^{+}\right)_{1}\right]_{\mathrm{X}}-\left[\left(\mathrm{p} S^{+}\right)_{1}\right]_{\mathrm{H}}=(-3.52 \pm 0.08)\left[\sigma^{\mathrm{n}}+(0.53 \pm 0.07) \Delta \sigma_{\mathrm{R}^{-}}\right]
$$

The high absolute value of the susceptibility constant of eq. $2(-3.52)$ provides evidence of a strong electronic effect on the mechanistic changeover; thus, for instance, in the case of electronwithdrawing substituents (i.e. compounds $\mathbf{1 i}-\mathbf{k}$ ), which slow down the uncatalyzed attack of the $N_{\alpha}$ atom to the oxadiazole ring by decreasing its nucleophilicity, the system is enforced to take the best possible advantage of every base approaching the proton on the same $N$-atom, anticipating the switch to the general-base-catalyzed pathway to lower and lower $\mathrm{p} S^{+}$values (i.e. as soon as the concentration of the basic species in the medium can show up its beneficial effects overcoming a "penalized" uncatalyzed process). As a rather spectacular result, $1 \mathbf{k}\left(\mathrm{X}=\mathrm{NO}_{2}\right)$, which is ca. 20 times less reactive than $1 \mathbf{a}(\mathrm{X}=4-\mathrm{OMe})$ at $\mathrm{p} S^{+} 3.80$ (uncatalyzed pathway), ${ }^{9 \mathrm{i}}$ becomes more than two powers of ten as reactive as the latter at $\mathrm{p} S^{+}>8$ (Figure 1). ${ }^{9 \mathrm{i}}$ 


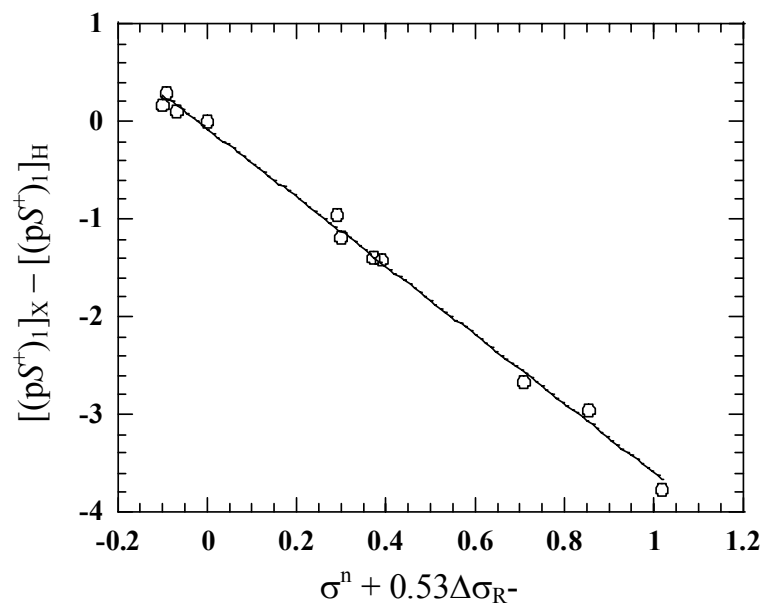

Figure 2. Plot of $\delta\left(\mathrm{p} S^{+}\right)_{1}$ \{i.e., $\left.\left[\left(\mathrm{p} S^{+}\right)_{1}\right]_{\mathrm{X}}-\left[\left(\mathrm{p} S^{+}\right)_{1}\right]_{\mathrm{H}}\right\}$ at $313.1 \mathrm{~K}$ versus $\left(\sigma_{\mathrm{H}}+r^{-} \Delta \sigma^{-}\right)$values (Yukawa-Tsuno plot, eq. 3) for the rearrangement of $\mathbf{1 a}-\mathbf{k}$ into $\mathbf{2 a}-\mathbf{k}$ in $\mathrm{D} / \mathrm{W}$.

On more quantitative grounds, the $\rho$ value of eq. 2 mirrors the reactivity crossover encompassing almost exactly the sensitivity to the electronic effects both of the base-catalyzed reactivity $\{\rho=2.30$, favoured by electron-withdrawing substituents; see eq. 2 in ref. $9 \mathrm{i}: \log$ $\left.\left(k_{\mathrm{A}, \mathrm{R}}\right)_{\mathrm{X}} /\left(k_{\mathrm{A}, \mathrm{R}}\right)_{\mathrm{H}}=2.30\left[\sigma_{\mathrm{H}}+0.64\left(\sigma^{-}-\sigma_{\mathrm{H}}\right)\right]\right\}$ and of the uncatalyzed one $[\rho=-1.24$, disfavoured by electron-withdrawing substituents; see eq 4 in ref. 9i: $\log \left(k_{\mathrm{A}, \mathrm{R}}\right)_{\mathrm{X}} /\left(k_{\mathrm{A}, \mathrm{R}}\right)_{\mathrm{H}}=-1.24\left(\sigma^{\mathrm{n}}+0.10\right.$ $\left.\left.\Delta \sigma_{R^{+}}+0.24 \Delta \sigma_{R^{-}}\right)\right]:$thus, $-3.52 \cong(-1.24-2.30)$, within the limits of the experimental error. ${ }^{20}$ Being at the borderline between the base-catalyzed and the uncatalyzed pathway, the $\left(\mathrm{p} S^{+}\right)_{1}$ values should be conceivably dominated essentially by electronic factors of the same nature as those influencing the reactivity on the two sides, i.e. at lower or higher $\mathrm{p} S^{+}$values. As a matter of fact, an excellent cross-correlation between $\delta\left(\mathrm{p} S^{+}\right)_{1}$ and $\log \left(k_{\mathrm{A}, \mathrm{R}}\right)_{\mathrm{X}} /\left(k_{\mathrm{A}, \mathrm{R}}\right)_{\mathrm{H}}$ at $\mathrm{p} S^{+} 3.80$ is observed whose large positive slope $(s=2.99$, Figure 9 in the S.I.) indicates that the factors which favor the uncatalyzed pathway [i. e. electron repulsion towards $N_{\alpha}$ to increase its nucleophilicity: higher $\left(k_{\mathrm{A}, \mathrm{R}}\right)_{\mathrm{u}}$ ] determine, as expected, "later" break-points [higher $\left(\mathrm{p} S^{+}\right)_{1}$, i.e. a wider range of prevalence of the uncatalyzed process itself]. On the other hand, a similar $\delta\left(\mathrm{p} S^{+}\right)_{1}$ versus $\log$ $\left(k_{\mathrm{A}, \mathrm{R}}\right)_{\mathrm{X}} /\left(k_{\mathrm{A}, \mathrm{R}}\right)_{\mathrm{H}}$ correlation at $\mathrm{p} S^{+} 11.50$ gives a likewise significant, although only somewhat less satisfactory, result; the negative susceptivity constant $(s=-1.64 \pm 0.08$, Figure 10 in the S.I.) indicates, in this case, that any electronic factors favouring the base-catalyzed pathway [i.e. electron withdrawal from $N_{\alpha}$ to facilitate the general-base-catalyzed pathway: higher $\left.\left(k_{\mathrm{A}, \mathrm{R}}\right)_{\mathrm{bc}}\right]$ determine "earlier" break-points [lower $\left(\mathrm{p} S^{+}\right)_{1}$, i.e. a narrower range of prevalence of the uncatalyzed process] restating from a different point of view the abovementioned proclivity of the system to switch to the base-catalyzed path as soon as possible. The significant positive deviation of $1 \mathrm{a}(\mathrm{X}=4-\mathrm{OMe})$ from the latter correlation reflects the enhanced nucleophilicity of $N_{\alpha}$ due to the electron release from the aryl substituent, which shows up notwithstanding the overwhelming electron density provided by the interaction of the $\mathrm{N}_{\alpha}-H$ proton with every base 
present in the reaction medium. Such a factor justifies the lack of a crossover between the reactivities of $1 \mathbf{a}$ and of the parent $1 \mathbf{d}(\mathrm{X}=\mathrm{H})$ : as a matter of fact, the latter proves less reactive both in the uncatalyzed and in the base-catalyzed region.

As far as the $\left(\mathrm{pS}^{+}\right)_{2}$ values for $\mathbf{1 a}-\mathbf{k}$ are concerned, we have observed an excellent IngoldYukawa-Tsuno correlation, treating data as suggested by Wepster ${ }^{19,21-22}$ (eq. 3: $n=11, r=$ 0.9984, $i=0.00 \pm 0.00$, C.L. $>99.9 \%$, Figure 3; see also Figure 11 of S.I.).

$\delta\left(\mathrm{p} S^{+}\right)_{2}=\left[\left(\mathrm{p} S^{\dagger}\right)_{2}\right]_{\mathrm{X}}-\left[\left(\mathrm{p} S^{+}\right)_{2}\right]_{\mathrm{H}}=(-0.43 \pm 0.01)\left[\sigma^{\mathrm{n}}+(0.17 \pm 0.05) \Delta \sigma_{\mathrm{R}^{+}}+(0.25 \pm 0.05) \Delta \sigma_{\mathrm{R}^{-}}\right](3)$

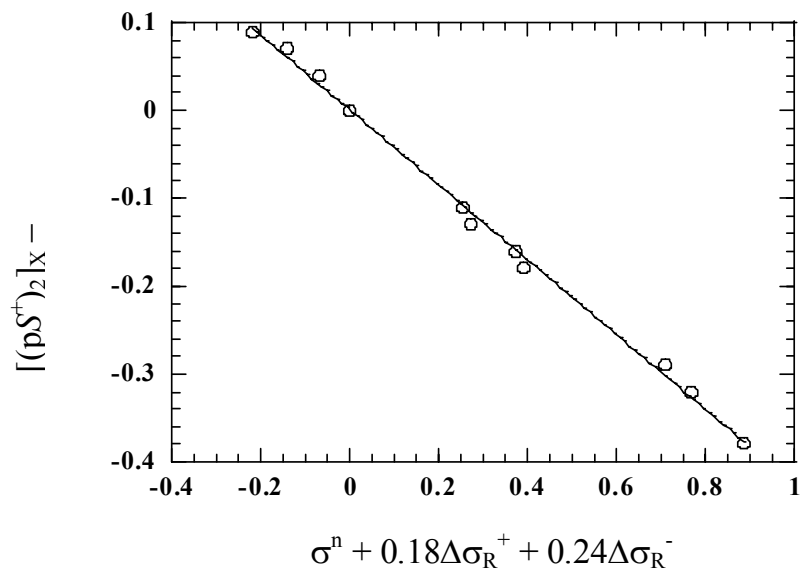

Figure 3. Plot of $\delta\left(\mathrm{p} S^{+}\right)_{2}$ \{i.e., $\left.\left[\left(\mathrm{p} S^{+}\right)_{2}\right]_{\mathrm{X}}-\left[\left(\mathrm{p} S^{+}\right)_{2}\right]_{\mathrm{H}}\right\}$ at $313.1 \mathrm{~K}$ versus $\left(\sigma^{\mathrm{n}}+r^{+} \Delta{\sigma_{\mathrm{R}}}^{+}+r^{-} \Delta \sigma_{\mathrm{R}}{ }^{-}\right)$ values (overall Ingold-Yukawa-Tsuno plot, eq 3 ) for the rearrangement of $\mathbf{1 a}-\mathbf{k}$ into $\mathbf{2 a}-\mathbf{k}$ in $\mathrm{D} / \mathrm{W}$.

As graphically evident from Figure 3, the slope of eq 3 indicates only a meager dependence of the $\left(\mathrm{p} S^{+}\right)_{2}$ break-point on the nature of $\mathrm{X}$ : an outcome properly rationalized on the grounds of the distance between the hydrazono aryl moiety and the site of acidic catalysis, localized on the $\mathrm{N}(4)$ atom of the oxadiazole ring. ${ }^{9}$ In this case, the negative sign mirrors a widening of the field of prevalence of the uncatalyzed pathway in the case of electron-withdrawing substituents, whose effect likely determines a somewhat decreased electron density on N(4) and thus a later appearance of the acid-catalyzed route while shifting towards lower $\mathrm{p} S^{+}$values.

Furthermore, as expected the Ingold-Yukawa-Tsuno treatment of the $\left(\mathrm{p} S^{\dagger}\right)_{2}$ data enlightens a tight analogy with the electronic factors that govern the reactivity on the two sides of the breakpoint itself, i.e. in the uncatalyzed and in the acid-catalyzed range. Consequently excellent correlations between $\delta\left(\mathrm{p} S^{+}\right)_{2}$ and $\log \left(k_{\mathrm{A}, \mathrm{R}}\right)_{\mathrm{X}} /\left(k_{\mathrm{A}, \mathrm{R}}\right)_{\mathrm{H}}$ measured at $\mathrm{p} S^{+} 3.80$ and at $\mathrm{p} S^{+} 1.00$ have been observed, characterized by very similar susceptibility constants $(s=0.35$ and 0.30 , respectively; Figures 12 and 13 in the S.I.); this outcome confirms the comparability of the substituent effect in the uncatalyzed and acid-catalyzed regions as supported by the excellent cross-correlation calculated $(s=1.16, r=0.999){ }^{9 \mathrm{i}}$ 
According to the reasoning developed above for the $\left(\mathrm{p} S^{+}\right)_{1}$ values, the susceptibility constant of eq. 3 should account for the differential sensitivity to the susbstituent effects between the uncatalyzed ( $\rho=-1.24$; see above) and the acid-catalyzed reactivity $[\rho=-1.43$, disfavoring electron-withdrawing substituents: see eq. 10 in ref. 9i: $\log \left(k_{\mathrm{A}, \mathrm{R}}\right)_{\mathrm{X}} /\left(k_{\mathrm{A}, \mathrm{R}}\right)_{\mathrm{H}}=-1.43\left(\sigma^{\mathrm{n}}+0.08\right.$ $\left.\left.\Delta \sigma_{R^{+}}+0.29 \Delta \sigma_{R^{-}}\right)\right]$. Actually, the difference between the two susceptibility constants $[-1.43-$ $(-1.24)$ ] yields a value $(-0.19)$ which only roughly approximates the experimental finding herein $(-0.43)$; such an outcome can be well justified on the grounds of the low absolute value of the susceptibility constant itself or, from a different point of view, on the grounds of the very similar effects played by $\mathrm{X}$ on the reaction pathways on the two sides of the $\left(\mathrm{p} S^{+}\right)_{2}$ break-point.

Finally $\delta\left(\mathrm{p} S^{+}\right)_{1}$ and $\delta\left(\mathrm{p} S^{+}\right)_{2}$ values cross correlate very nicely; the high and positive slope $(s=$ $8.44 \pm 0.44, n=11, i=-14.7 \pm 1.14, r=0.988$, C.L. $>99.9 \%)$ indicates that both $\delta\left(\mathrm{p} S^{+}\right)_{1}$ and $\delta\left(\mathrm{p} S^{+}\right)_{2}$ are governed by the similar substituent effect, which is much larger on the first than on the second one, as before qualitatively pointed out.

2) The $\left(\mathrm{p} S^{+}\right)_{1}$ values for $\mathbf{3 a}-\mathbf{k}$ (Table, in parentheses) show a numerical trend strictly comparable to that observed for 1a-k: accordingly, an excellent cross-correlation can be obtained between the two series of values; the practically unitary slope $(s=1.02$, Figure 14 in the S.I.) once more evidences the expected strongly similar behavior in the rearrangement of $\mathbf{1 a}-\mathbf{k}$ and $\mathbf{3 a}-\mathbf{k}$ in both the base-catalyzed and uncatalyzed regions, but for small differences in the absolute reactivities. $^{9 \mathrm{~d}, \mathrm{i}}$

3) As already outlined, looking at the $\Delta \mathrm{p} S^{+}$values (i.e. the width of the uncatalyzed region) for the rearrangement of $\mathbf{1 a}-\mathbf{k}$ (Table) one can observe a substituent-dependent fluctuation between 6.0 [for (Z)-hydrazones containing strongly electron-donating substituents, able to increase the nucleophilicity of $\mathrm{N}_{\alpha}$ ] and 2.4 [for $(Z)$-hydrazones containing strongly electron-withdrawing substituents, which lower the nucleophilicity of $\mathrm{N}_{\alpha}$ ]. Searching for a FER we obtained an excellent Yukawa-Tsuno relationship, again evidencing a significant contribution of throughresonance $^{19,22}$ from electron-withdrawing substituents (eq 4: $n=11, r=0.997, i=-0.08 \pm 0.04$, C.L. $>99.9 \%$, Figure 4; see also Figure 15 in S.I.).

$$
\delta\left(\Delta \mathrm{p} S^{+}\right)=\left(\Delta \mathrm{p} S^{+}\right)_{\mathrm{X}}-\left(\Delta \mathrm{p} S^{+}\right)_{\mathrm{H}}=(-3.11 \pm 0.08)\left[\sigma^{\mathrm{n}}+(0.53 \pm 0.07) \Delta \sigma_{\mathrm{R}^{-}}\right]
$$




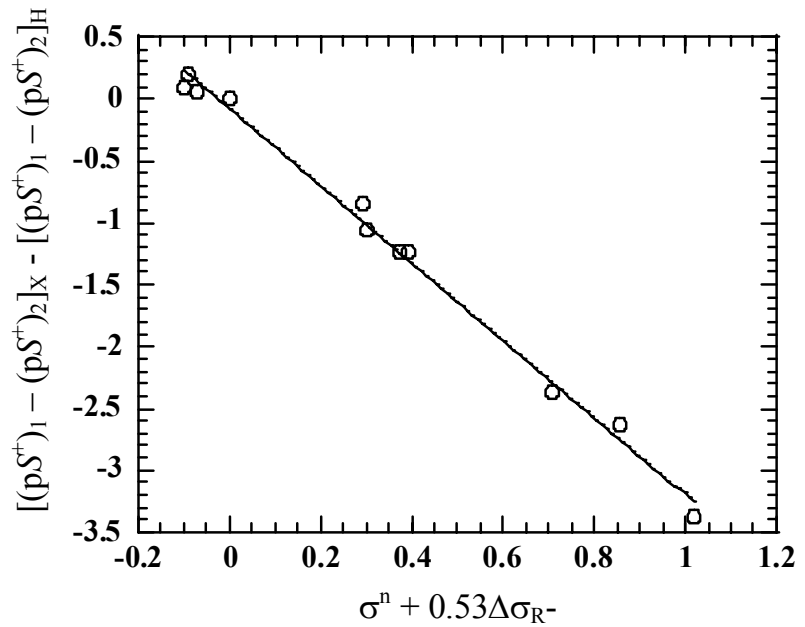

Figure 4. Plot of $\delta\left(\Delta \mathrm{p} S^{+}\right)$[i.e., $\left(\Delta \mathrm{p} S^{+}\right)_{\mathrm{X}}-\left(\Delta \mathrm{p} S^{+}\right)_{\mathrm{H}}$ ] at $313.1 \mathrm{~K}$ versus $\left(\sigma_{\mathrm{H}}+r^{-} \Delta \sigma^{-}\right)$values (Yukawa-Tsuno plot, eq 4) for the rearrangement of $\mathbf{1 a}-\mathbf{k}$ into $\mathbf{2 a}-\mathbf{k}$ in $\mathrm{D} / \mathrm{W}$.

Moreover good cross-correlations versus the data concerning both the reactivity at $\mathrm{p} S^{+} 11.50$ (that is in the base-catalyzed region: $s=-1.45$, see Figure 16 in the S.I.), at $\mathrm{pS}^{+} 3.80$ (that is for the uncatalyzed pathway: $s=2.64$, see Figure 17 in the S.I.), and at $\mathrm{p} S^{+} 1.00$ (that is in the acidcatalyzed region: $s=2.29$, see Figure 18 in the S.I.), have been observed. Once more the sign of the slope is positive in the cross-correlations versus the reactivity in the uncatalyzed and acidcatalyzed regions, negative in the cross-correlation versus the reactivity in the base-catalyzed region, as expected considering the signs of the relevant FER in the three regions. ${ }^{9 \mathrm{i}}$

Interestingly enough in this case the calculated susceptibility constant appears dependent on the substituent effect on all of the three reaction pathways. As a matter of fact, taking into account the relevant uncertainties and the modest contribution of extra-conjugative effects, the slope calculated (eq 4: $-3.11 \pm 0.08$ ) results to be the algebraic difference between those of eqs 2 $(-3.52 \pm 0.08)$ and $3(-0.43 \pm 0.01)$, that is, $\rho_{\left(\Delta \mathrm{p} S^{+}\right)} \cong \rho_{(\mathrm{p} S+) 1}-\rho_{(\mathrm{p} S+) 2}$. This result well agrees with the considerations developed under point 1 .

\section{Conclusions}

By using previous kinetic results on the MRH of a series of (Z)-arylhydrazones of 5-amino-3benzoyl-1,2,4-oxadiazole (1a-k) into the relevant (2-aryl-5-phenyl-2H-1,2,3-triazol-4-yl)ureas $(\mathbf{2 a}-\mathbf{k})$ at different $\mathrm{p} S^{+}$values in $\mathrm{D} / \mathrm{W}$ at $313.1 \mathrm{~K},{ }^{9 \mathrm{i}}$ the break-points for the changeover between mechanisms and the $\mathrm{p} S^{+}$widths of existence of the uncatalyzed process have been calculated. From their correlation (FER's) to the electronic effects of the substituent, the considerations hereinafter can be drawn, allowing a deeper understanding of the $\mathrm{S}_{\mathrm{N}} \mathrm{i}$ process involved. 
1) The changeover from the base-catalyzed to the uncatalyzed path $\left[\left(\mathrm{p} S^{\dagger}\right)_{1}\right]$ as well as from the uncatalyzed to the acid-catalyzed path $\left[\left(\mathrm{pS}^{\dagger}\right)_{2}\right]$ are substituent-dependent and for the first time it has been possible to provide evidence of the occurrence of FER's between the values of the relevant break-points and the electronic effect of the substituents.

2) As a direct consequence of the above observations for the first time it has been ascertained that the width of the uncatalyzed region $\left(\Delta \mathrm{p} S^{+}\right)$is in turn substituent-dependent; moreover, an interesting relationship with $\rho_{(\mathrm{p} S+) 1}$ and $\rho_{(\mathrm{p} S+) 2}$ values $\left[\rho_{(\Delta \mathrm{p} S+)}=\rho_{(\mathrm{p} S+) 1}-\rho_{(\mathrm{p} S+) 2}\right]$ has been brought to evidence.

3) Interestingly enough one can observe that at a selected $\mathrm{p} S^{+}$value $\mathbf{1 a}-\mathbf{k}$ can show behaviors completely different among themselves as far as the absolute reactivity and/or the reaction pathway involved are concerned: a comparison between the reactivity of $\mathbf{1 k}$ and $\mathbf{1 a}$ (Fig. 1) is particularly significant at this regard.

Much more interestingly, the results herein can offer information of general applicability, as both catalysis and understanding of catalytic processes play a central role in the fields of chemical and biological sciences. In particular our findings could be useful in order to gain insight into the mechanism of complex biological processes such as the enzymatic ones.

As a matter of fact, small structural variations in the substrate can cause dramatic changes of the enzymatic activity in biological systems: our system can thus be regarded as a model of how such variations can exalt or depress (or even suppress) a particular reaction path, being provided of suitable reaction centers (a basic site, an acidic site, and a nucleophilic one) which can be "activated" in different environmental conditions.

\section{Experimental Section}

Calculations. The FER calculations have been carried out firstly attempting a simple Hammett ${ }^{12 b}$ approach, then considering only the 3-substituted (Z)-phenylhydrazones and finally applying the appropriate Yukawa-Tsuno ${ }^{18}$ or Ingold-Yukawa-Tsuno ${ }^{18-19,21}$ treatment to all of the substrates.

\section{Supplementary Information Available}

FER plots concerning $\log k_{\mathrm{A}, \mathrm{R}}\left(\right.$ at $\mathrm{p} S^{+}=11.5,3.8$, and 1.0$), \delta\left(\mathrm{p} S^{+}\right)_{1}, \delta\left(\mathrm{p} S^{+}\right)_{2}$, and $\delta \Delta \mathrm{p} S^{+}$. This material is available free of charge via the Internet at http://www.arkat-usa.org. 


\section{Acknowledgements}

We thank for financial support MIUR (Roma) (PRIN 20066034372) and the Universities of Bologna, Genova and Palermo.

\section{References and Notes}

1. (a) Trost, B. M.; Fleming, I. Eds., Comprehensive Organic Synthesis, Pergamon, 1991. (b) Katritzky, A. R.; Rees, C. W. Eds., Comprehensive Heterocyclic Chemistry I, Pergamon; Katritzky, A. R.; Rees, C. W.; Scriven, E. F. V. Eds., Comprehensive Heterocyclic Chemistry II, Pergamon, 1982-1995.

2. (a) Van der Plas, H. C. Ring Transformations of Heterocycles; Academic Press: London, 1973; Vols. 1 and 2. (b) L'abbé, G. J. Heterocycl. Chem. 1984, 21, 627.

3. (a) Dondoni, A. In Modern Synthetic Methods; Scheffold, R., Ed.; Verlag Helvetica Chimica Acta: Basel, Switzerland, 1992; pp 377. (b) Dondoni, A.; Marra, A. In Preparative Carbohydrate Chemistry; Hanessian, S., Ed.; M. Dekker: New York, 1997; Chapter 9, pp 173. (c) Patai, S.; Rappoport, Z. Eds., The Chemistry of Functional Groups, (a series of monographs edited between 1992 and 2006) Wiley. (d) Chemical Reviews has dedicated an issue to the Chemistry of heterocyclic compounds (Katritzky, A. R., Ed. Chem. Rev. 2004, 104, 2125) well evidencing their role in organic synthesis.

4. (a) Ruccia, M.; Vivona, N.; Spinelli, D. Adv. Heterocycl. Chem. 1981, 29, 141. (b) Vivona, N.; Buscemi, S.; Frenna, V.; Cusmano, G. Adv. Heterocycl. Chem. 1993, 56, 49. (c) Boulton, A. J. Lectures in Heterocyclic Chemistry; Hetero-Corporation: Provo, UT, 1973. (d) Boulton, A. J.; Katritzky, A. R.; Majid-Hamid, A. J. Chem. Soc. C 1967, 2005. (e) Katritzky, A. R.; Gordev, M. F. Heterocycles 1993, 35, 483. (f) Vivona, N.; Buscemi, S. Heterocycles 1992, 41, 2095.

5. (a) Andreani, A.; Granaiola, M.; Leoni, A.; Locatelli, A.; Morigi, R.; Rambaldi, M.; Garaliene, V.; Farruggia, G.; Masotti, L. Bioorg. Med. Chem. 2004, 12, 1121. (b) Budriesi, R.; Cosimelli, B.; Ioan, P.; Lanza, C. Z.; Spinelli, D.; Chiarini, A. J. Med. Chem. 2002, 45, 3475. (c) Budriesi, R.; Carosati, E.; Chiarini, A.; Cosimelli, B.; Cruciani, G.; Ioan, P.; Spinelli, D.; Spisani, R. J. Med. Chem. 2005, 48, 2445. (d) Li, Z.; Yang, Q.; Qian, X. Bioorg. Med. Chem. 2005, 13, 3149. (e) Almajan, G. L.; Innocenti, A.; Puccetti, L.; Manole, G.; Barbuceanu, I. S.; Scozzafava, A.; Supuran, C. T. Bioorg. Med. Chem. Lett. 2005, 15, 2347. (f) Luisi, R.; Capriati, V.; Degennaro, L.; Florio, S. Org. Lett. 2003, 5, 2723.

6. (a) Velik, J.; Baliharová, V.; Fink-Gremmels, J.; Bull, S.; Lamka, J.; Skálová, L. Res. Veterinary Science 2004, 76, 95. (b) Tapia-Salazar, M.; Smith, T. K.; Harris, A.; RicqueMarie, D.; Cruz-Saurez, L.-E. Aquaculture 2001, 139, 281.

7. (a) Wu, C.-C.; Chang, C.-F.; Bai, S. J. Thin Solid Films 2005, 479, 245. (b) Yu, B.-Z.; Li, H.L.; Zhang, Y. F. Thin Solid Films 2005, 476, 331. (c) Zhang, D.-Q.; Gao, L.-X.; Zhou, G.-D. 
Corrosion Science 2004, 46, 3031. (d) Mashraqui, S. H.; Kenny, R. S.; Ghadigaonkar, S. G.; Krishnan, A.; Bhattacharya, M.; Das, P. K. Optical Materials 2004, 27, 257. (e) Beccalli, E.; Broggini, G.; Contini, A.; De Marchi, I.; Zecchi, G.; Zoni, C. Tetrahedron Asymmetry 2004, 15, 3181 .

8. (a) Vivona, N.; Buscemi, S. Heterocycles 1995, 41, 2095. (b) Pace, A.; Pibiri, I.; Buscemi, S.; Vivona, N. Heterocycles 2004, 63, 2627. (c) Buscemi, S.; Pace, A.; Pibiri, I.; Vivona, N.; Spinelli, D. J. Org. Chem. 2003, 68, 605. (d) Buscemi, S.; Pace, A.; Pibiri, I.; Vivona, N.; Caronna, T. J. Fluorine Chem. 2004, 125, 165. (e) Buscemi, S.; Pace, A.; Pibiri, I.; Vivona, N. J. Org. Chem. 2002, 67, 6253. (f) Buscemi, S.; Pace, A.; Palumbo Piccionello, A.; Macaluso, G.; Vivona, N.; Spinelli, D.; Giorgi, G. J. Org. Chem. 2005, 70, 3288.

9. (a) Spinelli, D.; Corrao, A.; Frenna, V.; Vivona, N.; Ruccia, M.; Cusmano, G. J. Heterocycl. Chem. 1976, 13, 357. (b) Spinelli, D.; Frenna, V.; Corrao, A.; Vivona, N. J. Chem. Soc., Perkin Trans. 2 1978, 19. (c) Frenna, V.; Vivona, N.; Consiglio, G.; Corrao, A.; Spinelli, D. J. Chem. Soc., Perkin Trans. 2 1981, 1325. (d) Frenna, V.; Vivona, N.; Corrao, A.; Consiglio, G.; Spinelli, D. J. Chem. Res. Synop. 1981, 308; Miniprint 3550. (e) Frenna, V.; Vivona, N.; Consiglio, G.; Spinelli, D. J. Chem. Soc., Perkin Trans. 2 1983, 1199. (f) Cosimelli, B.; Frenna, V.; Guernelli, S.; Lanza, C. Z.; Macaluso, G.; Petrillo, G.; Spinelli, D. J. Org. Chem. 2002, 67, 8010. (g) Bottoni, A.; Frenna, V.; Lanza, C. Z.; Macaluso, G.; Spinelli, D. J. Phys. Chem. A 2004, 108, 1731. (h) D’Anna, F.; Ferroni, F.; Frenna, V.; Guernelli, S.; Lanza, C. Z.; Macaluso, G.; Pace, V.; Petrillo, G.; Spinelli, D.; Spisani, R. Tetrahedron 2005, 61, 167. (i) D’Anna, F.; Frenna, V.; Macaluso, G.; Marullo, S.; Morganti, S.; Pace, V.; Spinelli, D.; Spisani, R.; Tavani, C. J. Org. Chem. 2006, 71, 5616. (j) Fontana, A.; Guernelli, S.; Lo Meo, P.; Mezzina, E.; Morganti, S.; Noto, R.; Rizzato, E.; Spinelli, D.; Zappacosta, R. Tetrahedron 2008, 64, 733. (k) Pace, A.; Pibiri, I.; Palumbo Piccionello, A.; Buscemi, S.; Vivona, N.; Barone, G. J. Org. Chem. 2007, 72, 7656.

10. An operational $\mathrm{pH}$ scale, $\mathrm{p} S^{+}$(see Bates, R. G. Solute-Solvent Interactions; Coetze, J. F., Ritchie, C. D., Eds.; Marcel Dekker: New York, 1969; p 46), was established in aqueous dioxane by employing the $\mathrm{p} K_{\mathrm{a}}$ values of acids determined by interpolation from the data reported by H. S. Harned and B. B. Owen (The Physical Chemistry of Electrolytic Solution, 3rd ed.; ACS Monograph No. 137; Reinhold: New York, 1970; pp 716, 755). For details see ref. 9a.

11. Recently Terrier and Coworkers (Mokhtari, M.; Goumont, R.; Hallé, J. C.; Terrier, F. Arkivoc, 2002, 168) have illustrated a nice example of $\mathrm{pH}$-dependent multiform catalysis examining the covalent hydration of a benzofuroxan derivative.

12. (a) Laidler, K. J. Chemical Kinetics; McGraw-Hill: London, 1965; pp 450. (b) Hammett, L. P. Physical Organic Chemistry, $2^{\text {nd }}$ ed; McGraw-Hill: New York, 1970; Chapter 10. (c) Laidler, K. J.; Bunting, P. S. The Chemical Kinetics of Enzyme Action; Clarendon Press: Oxford, 1973: pp 60. (d) Ritchie, C. D. Physical Organic Chemistry, The Fundamental Concepts; M. Dekker: New York, 1975, chapter 7. (e) Exner, O. Correlation Analysis of Chemical Data; Plenum Press: New York and London, 1988, chapter 7.4. (f) Williams, A. 
Concerted Organic and Bio-organic Mechanism; CRC Press: Boca Baton, FL, 2000. (g) Carey, F. A.; Sundberg, R. J. Advanced Organic Chemistry; Kluwer Academic/Plenum Publishers: NewYork, 2000; Chapter 4.8; (h) Williams, A. Free Energy Relationships in Organic and Bio-organic Chemistry; RSC: Cambridge, UK, 2003. (i) Anslyn, E. V.; Doughherty, D. A. Modern Physical Organic Chemistry, University Science Books, Sausalito, Ca., USA, 2006. (j) Skrabal, A. Z. Elektrochem., 1927, 33, 322.

13. (a) See ref. 11i, pp. 101. (b) Horváth, K.; Korbonits, D.; Náray-Szabó, K.; Simon, K. Theochem 1986, 136, 215. (c) Galli, C.; Mandolini, L. Eur. J. Org. Chem., 2000, 3117.

14. $2 H$-1,2,3-Triazole is much more aromatic than 1,2,4-oxadiazole (aromaticity indexes: $\mathrm{I}_{\mathrm{A}}, 109$ and 48, respectively. From Bird, C. W. Tetrahedron, 1992, 48, 335). See also, Balaban, A. T.; Oniciu, D. C.; Katritzky, A. R. Chem. Rev. 2004, 104, 2777.

15. In the rearrangement of (Z)-hydrazones $3 \mathbf{a}-\mathbf{k}$ into the triazoles $4 \mathbf{a}-\mathbf{k}$ the presence of an amido group at $\mathrm{C}(4)$ in the final 1,2,3-triazole ring was found to play a parallel favorable role. $^{4,9,13}$

16. (a) See ref. 11i, p 496. (b) Kirby, A. J. Adv. Phys. Org. Chem., 1980, 17, 183. (c) Kirby, A. Angew. Chem., Int. Ed. Engl. 1996, 35, 707. (d) Illuminati, G.; Mandolini, L. Acc. Chem. Res., 1981, 14, 95. (e) Mandolini, L. Adv. Phys. Org. Chem. 1986, 22, 1. (f) Cacciapaglia, R.; Di Stefano, S.; Mandolini, L. Acc. Chem. Res. 2004, 37, 113.

17. Considering that $\left(\mathrm{p} S^{+}\right)_{1}$ and $\left(\mathrm{p} S^{+}\right)_{2}$ are functions of $\log k_{\mathrm{A}, \mathrm{R}}$ of the concerned reactions the relationships as a function of the present substituents would be regarded as FERs.

18. (a) Tsuno, Y.; Ibata, T.; Yukawa, Y. Bull. Chem. Soc. Jpn. 1959, 32, 960. (b)Yukawa, Y.; Tsuno, Y. Bull. Chem. Soc. Jpn. 1959, 32, 965. (c) Yukawa, Y.; Tsuno, Y.; Sawada, M. Bull. Chem. Soc. Jpn. 1966, 39, 2274. (d) Yukawa, Y.; Tsuno, Y.; Sawada, M. 1972, 45, 1198.

19. (a) Wepster, B. M. J. Amer. Chem. Soc. 1973, 95, 102. (b) Hoefnagel, A. J.; Monshouwer, J. C.; Snorn, E. C. G.; Wepster, B. M. J. Amer. Chem. Soc. 1973, 95, 5350. (c) Hoefnagel, A. J.; Wepster, B. M. J. Amer. Chem. Soc. 1973, 95, 5357.

20. The use of different substituent parameters $\left(\sigma_{H}\right.$ or $\left.\sigma^{\mathrm{n}}\right)$ for the optimized FER relationships being compared herein should not significantly affect the values of the susceptibility constants involved. ${ }^{9 \mathrm{j}}$

21. Ingold, C. K. Structure and Mechanism in Organic Chemistry, 1969, Cornell University Press, Ithaca, $2^{\text {nd }}$ edn., pp 1217.

22. Brown, H. C.; Okamoto, Y. J. Amer. Chem. Soc. 1958, 80, 4979. 